\title{
COMPARISON OF TIDAL CURRENTS UNDER DIFFERENT NOURISHMENT SCHEMES AT WEST BEACH OF BEIDAIHE, CHINA
}

\author{
Yu Zhang ${ }^{1}$, Cuiping Kuang ${ }^{2, *}$, Lulu He ${ }^{2, *}$, Yi Pan ${ }^{2}$, Yanxiong Yang ${ }^{3}$, Jiabo Zhang ${ }^{3}$ and Shuguang Liu $^{2}$
}

\begin{abstract}
This paper detailed a study on the tidal current field around a beach nourishment project including submerged breakwaters and jetties. The effect of different nearshore structure arrangements on the tidal current field is studied utilizing a numerical model established based on the solution of two-dimensional shallow water equations and an unstructured grid. In order to calibrate the numerical model, the field survey was conducted at 5 tidal current stations and a tidal level station around the project area. According to a primary analysis on stability, environment, sight of the beach, and construction quantity, four project schemes are chosen and simulated. After comparing the modeling results, the effects of submerged breakwaters and jetties are discussed. Conclusively, it is feasible to protect the filled sand on West Beach by jetties and submerged breakwaters through obvious tidal current velocity reduction in the nearshore area.
\end{abstract}

Keywords: beach nourishment; tidal current field; West Beach in Beidaihe

\section{INTRODUCTION}

Beaches are one of the most important tourism resources, which is a lovely place for people to travel and relax. However, erosion of beaches has become troublesome in the recent decades. An estimate made by Bird (1985) shows that about $70 \%$ of the world's sandy beaches are retreating at a rate of $0.5 \sim 1.0 \mathrm{~m}$ a year. While according to van der Salm and Unal (2003), 95\% of the world beaches are eroding due to human activities and moving dynamics.

In general, tidal currents do not cause beach erosion or deposition directly, but they carry sediment along the coast in the nearshore zone, and this may eventually be delivered to beaches alongshore (Bird, 2008). For this reason, tidal currents may play a certain role in some beach erosion cases.

The attraction force of the Moon and the Sun that exerted on the Earth's hydrosphere causes ocean tides. Tidal currents are produced in coastal settings when the tidal wave becomes constricted, such as at the entrance to a bay or tidal inlet (Davis Jr and FitzGerald, 2004). Simply speaking, tidal current is a periodic horizontal motion of sea water under the effect of tidal force caused by the Sun and the Moon. The study of numerical tidal current model can be traced back to 1960s in the world and 1970s in China. The three-dimensional numerical tidal current model based on Reynolds Averaged N-S Equations is widely known as an effective model to study general free surface flow, but it is limited by the capacity and performance of computer for the fine calculation of the model in large scale, especially in a model coupled with wind wave, sediment transport and bed deposition and erosion. In the coastal zone, the vertical scale of coastal tidal current is much smaller than the horizontal one, so the vertical acceleration term can be ignored. According to the shallow water assumption, a two-dimensional tidal current model can be given out. The two-dimensional numerical tidal current model has been widely used in some regions such as to study the rule of tide and tidal current (Cao and Fang, 1990; Zhang, et al., 2007), to compute the tidal current field around coastal engineering (Wan and Li, 2000; Shi and Li, 2003) and environmental engineering (Liu et al., 2009; Gu and Kuang, 1996).

So far, plenty of numerical models have been developed and have been able to simulate the tidal current, such as CH3D (Sheng, 1986), POM (Blumberg and Mellor, 1987), ADCIRC (Luettich et al, 1991), EFDC (Hamrick, 1992), FVCOM (Chen et al., 2003), ELCIRC (Zhang et al., 2004), MIKE3Flow (DHI Hydraulics, 2005), Delft3D-Flow (WL | Delft Hydraulics, 2006), SELFE (Zhang and Baptista, 2008), and so on. Generally speaking, those models use the following methods: 1) curvilinear orthogonal grid or unstructured triangular grid; 2) finite difference (FD), finite volume (FV) or finite element (FE) for the space discretization method (SDM);3) upwind scheme, Lagrange method, central difference (CD) method or Crank-Nicolson method to solve the advection term; and 4) ADI, semiimplicit theta, Crank-Nicolson, Rungga-Kutta, or Euler et al. for the time discretization method.

\footnotetext{
${ }^{1}$ School of Resources and Safety Engineering, China University of Mining and Technology, No.11 Xueyuan Road, Beijing 100083, China

2 Department of Hydraulic Engineering, School of Civil Engineering, Tongji University, No.1239 Siping Road, Shanghai, 200092, China. * Corresponding authors, Email:cpkuang@tongji.edu.cn and lulu-stin@163.com

${ }^{3}$ Qinhuangdao Mineral Resource and Hydrogeological Brigade, Hebei Geological Prospecting Bureau, No.221 Yanshan Road, Qinhuangdao, Hebei Province, 066001, China
} 
In this paper, a two-dimensional numerical tidal current model is established based on the solution of two-dimensional shallow water equations. Unstructured triangular grids are utilized in the modeling. Field survey of current and tidal field is conducted to calibrate the numerical model. With the calibrated model, four different schemes with different arrangements of nearshore structures are simulated. After comparing the modeling results, the effects of submerged breakwaters and jetties are discussed.

\section{STUDY AREA}

West Beach locates in the southwest of Beidaihe District of Qinhuangdao City, which is in the west of Bohai Bay (Fig. 1), Hebei Province, China. Beidaihe District has a shoreline of totally $18.4 \mathrm{~km}$ long and it is famous for its wide beach, soft sand and mild wave. West Beach locates in the northeast of Dai river, with several famous and scenic bathing places lying on (Fig. 1). It is characterized by relatively short (about $3.5 \mathrm{~km}$ in length) embayed beach bound on either extremity by headlands; at the southwest end of the beach there is a jetty used to lead the flow of Dai river; at the northeast of the beach there is a cape, where there used to be a jetty which was dismantled in 2002.

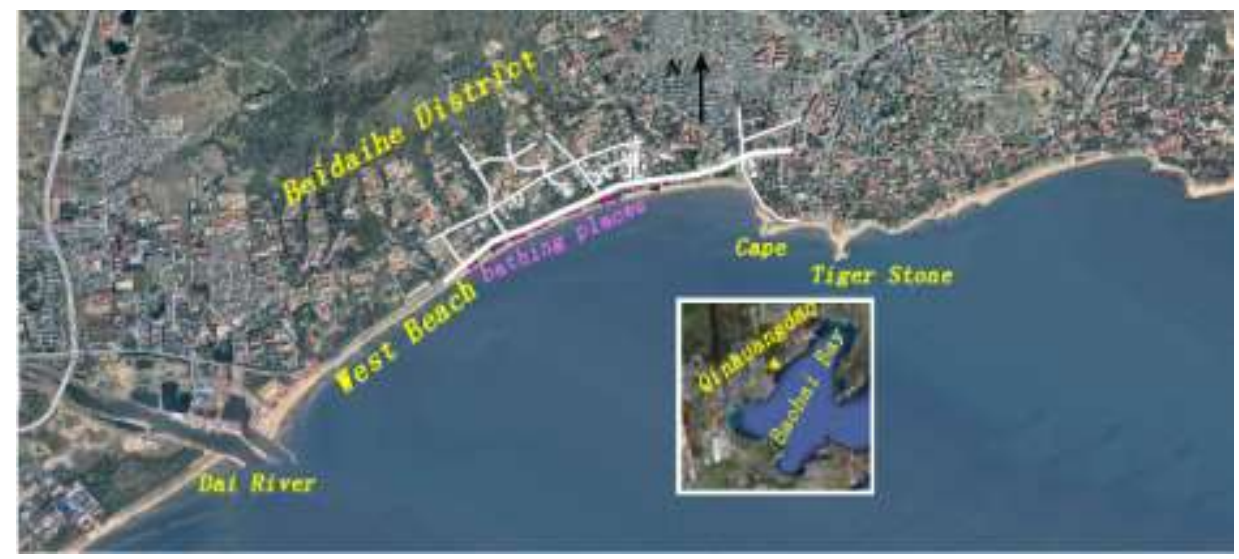

Figure 1. Study area.

According to the economic statics, about 2/3 tourism income in Qinhuangdao City is from beach tourism, reported by Qinhuangdao Mineral Resource and Hydrogeological Brigade (2009). However the beach has been eroding since 1950s, with sand coarsening, rock outcropping and slope steepening. It is recorded that the width of West Beach had a average width of about $110 \mathrm{~m}$ in the 1960s; its average width is around $55 \mathrm{~m}$ with the maximum width of $76 \mathrm{~m}$ and minimum width of $26 \mathrm{~m}$ in the 1980s; in 2000, the maximum width of West Beach is $58 \mathrm{~m}$ and the minimum width is only $15 \mathrm{~m}$; and in 2007, its average width is only $17 \mathrm{~m}$, which is 93 m narrow compared to 1960s. If no improvement is applied, the beach might disappear soon. Recognizing the importance of Beidaihe's beaches to tourism and the economical benefit to the City of Qinhuangdao, the local government initiated a beach nourishment project to protect and enlarge the beaches in 2007.

\section{PROJECT DESCRIPTION}

This project is a planned beach nourishment project for the whole West Beach. According to a primary analysis on stability, environment, sight of the beach, and construction quantity, an initial plan of 50m-wide beach nourishment with jetties and submerged breakwaters is proposed: the jetties are designed to be built on the extremities of the beach, and a channel for tidal current is reserved in the east jetty. The submerged breakwaters are designed to be built in $-4 \mathrm{~m}$ depth sea area, about $450 \mathrm{~m}$ off the seashore; the crest of the breakwater is $1.5 \mathrm{~m}$ below the mean sea level. Some of the borrowed sands are gotten from the dredging of nearby rivers and navigation channels, and the other from sea bed of $15 \mathrm{~m}$ depth area off the West Beach. The median grain size of the borrowed sands ranges between 0.42 and $0.61 \mathrm{~mm}$, while the median grain size of the native beach is $0.34 \mathrm{~mm}$. The designed beach slope is 1:10 below low water level and 1:8 above low water level. Designed berm height is $3 \mathrm{~m}$ (China's 1985 national height datum) and filled sand volume is $256.7 \times 10^{4} \mathrm{~m}^{3}$ with an overfilling factor of 1.12 , which are calculated according to Coastal Engineering Manual. 


\section{METHODOLOGY}

\section{Field survey}

A total of 5 current stations were set in the nearshore area around West Beach, as shown in Fig. 2. The water depth at the current stations ranges from $5 \mathrm{~m}$ to $15 \mathrm{~m}$. Current directions and velocities were taken once an hour at the stations. A tide level station was set on the coast of Qinhuangdao near Qinhuangdao Harbor. Tidal level data were also recorded each hour. All the data collections were conducted by Qinhuangdao Mineral Resource and Hydrogeological Brigade, Hebei Geological Prospecting Bureau, China.

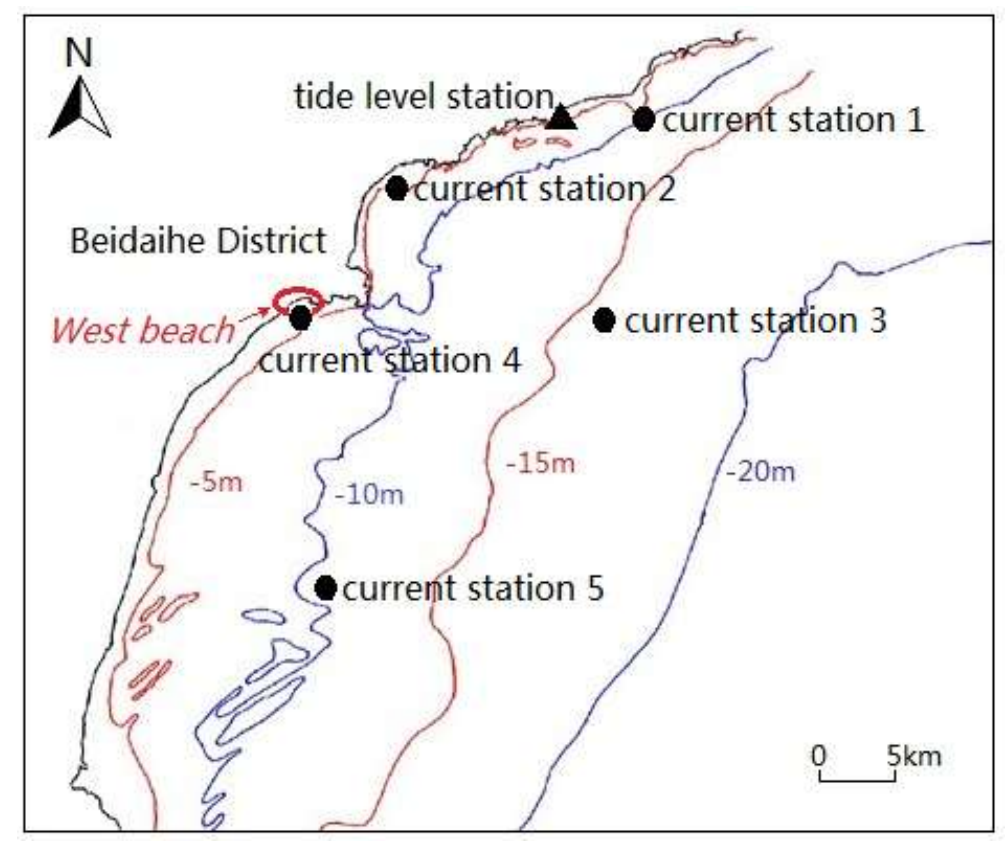

Figure 2. Survey station and water depth contour around West Beach in Beidaihe.

Current and tidal level measurements in a typical day (from 2007-7-27 7:00 to 2007-7-28 7:00) are shown in Fig. 3 and Fig. 4. As seen, the current direction changes four times a day, therefore the tidal flow type is dominated as semi-diurnal tidal current; since there is only one maximum value and one minimum value in 24 hours for the tidal level, the tidal type is diurnal tide.

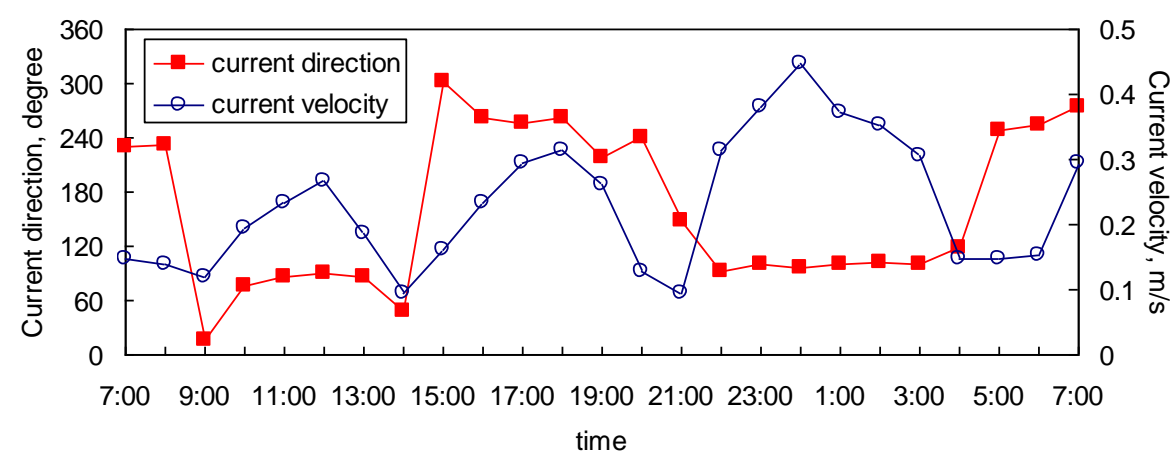

Figure 3. Current direction and velocity measurements at current station 1 in 24 hours (from 2007-7-27 7:00 to $2007-7-28$ 7:00). 


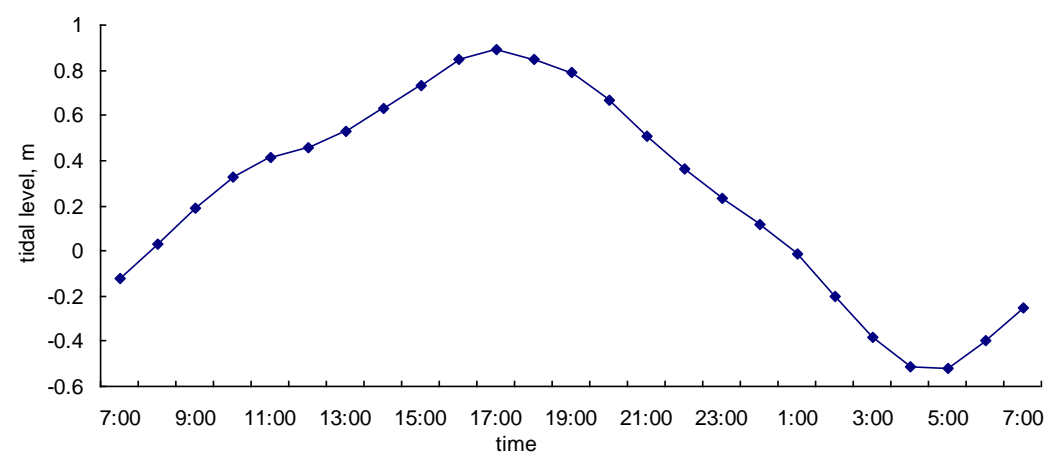

Figure 4. Tidal level measurements in 24 hours (from 2007-7-27 7:00 to 2007-7-28 7:00).

\section{Model description}

The simulation of current near the project area was conducted by using a numerical model based on the solution of two-dimensional shallow water equations which means the two-dimensional impressible shallow water equations are obtained under hydrostatic pressure and Boussinesq assumption through integrating 3D horizontal momentum equations and the continuity equation over depth $h=\eta+d$ :

$$
\begin{gathered}
\frac{\partial h}{\partial t}+\frac{\partial h \bar{u}}{\partial x}+\frac{\partial h \bar{v}}{\partial y}=0 \\
\frac{\partial h \bar{u}}{\partial t}+\frac{\partial h \bar{u}^{2}}{\partial x}+\frac{\partial h \overline{v u}}{\partial y}=f \bar{v} h-g h \frac{\partial \eta}{\partial x} \\
+\frac{\tau_{s x}}{\rho_{0}}-\frac{\tau_{b x}}{\rho_{0}}+\frac{\partial}{\partial x}\left(h T_{x x}\right)+\frac{\partial}{\partial y}\left(h T_{x y}\right) \\
\frac{\partial h \bar{v}}{\partial t}+\frac{\partial h \bar{v}^{2}}{\partial y}+\frac{\partial h \overline{v u}}{\partial x}=-f \bar{u} h-g h \frac{\partial \eta}{\partial y} \\
+\frac{\tau_{s y}}{\rho_{0}}-\frac{\tau_{b y}}{\rho_{0}}+\frac{\partial}{\partial x}\left(h T_{x y}\right)+\frac{\partial}{\partial y}\left(h T_{y y}\right)
\end{gathered}
$$

where $\eta$ is the surface elevation; $d$ is the still water depth; $h=\eta+d$ is the total water depth; $f=2 \Omega \sin \varphi$ is the Coriolis parameter; $T_{i j}$ is the lateral stresses.

\section{MODELING}

\section{Model establishment}

For evaluating the arrangement of submerged breakwaters and jetties, a two-dimensional tidal current model is established to simulate the tidal current field around the beach nourishment project.

Fig. 5 shows the computational grid, which is build using unstructured triangular grid technique, covering an area of $3,000 \mathrm{~km}^{2}$ and including all the 5 tidal current stations and one tidal level station. As shown in Fig. 5, a nested grid is used, i.e. a coarse grid is built covering all the current stations, and a fine grid is built around the West Beach. The coarse grid is built in two levels: around the fine grid is the finer and near the open boundaries is coarser. Three open boundaries are set on east, south, and west of the coarse grid, as seen in Fig. 5. 


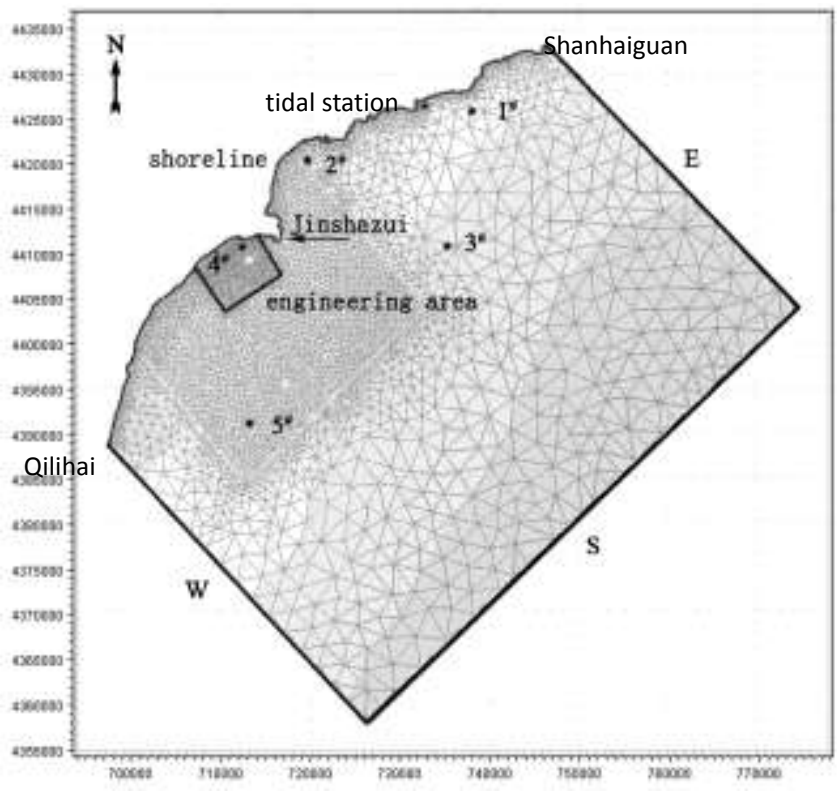

Figure 5. Nested computational grid.

An explicit method is used to solve governing equations. The use of explicit method introduces a restriction on the time step for a given spatial discretiztion due to the CFL stability condition. This can be simply described as the following equation:

$$
C r=\sqrt{g h} \frac{\Delta t}{\Delta L} \leq 0.5
$$

Hence the time step of the model is set to $5 \mathrm{~s}$. A horizontal eddy viscosity value $20 \mathrm{~m}^{2} / \mathrm{s}$ is applied. And a Manning Coefficient of 0.0015 is used for the roughness coefficient to match the average roughness of the bed sediment.

In order to save computational time and get more accurate results, nested grid is used. A large-scale model is built to employ all the field survey data to get a verified large-scale current field and provides boundary conditions for small-scale model. A small-scale model is employed to get detailed current field around West Beach under different project schemes.

\section{Model calibration and verification}

Current field is simulated in the large-scale model for model calibration and providing boundary conditions for the small-scale model. Current stations 1 to 5 are marked up in Fig. 5 as $1 \#$ to 5\#. The measured data of water level from 2007-7-27 5:00 to 2007-7-28 11:00 and the measured data of tidal current at station 3 and 5 are used to calibrate the model while the measured data of water level from 2007-7-28 0:00 to 2007-7-29 11:00 and the measured data of tidal current at station 1, 2 and 4 are used to validate the model.

Fig. 6 shows the comparison between simulated and observed water level in the tidal level station. The simulation results represent a well-matched tendency in water level. Fig. 7 shows the comparison between simulated and observed tidal current velocity magnitude and direction at two selected stations for model calibration. The results show that the tide in model is diurnal while the tidal current is semidiurnal, which indicates the tidal current is complex. Using the same model and parameters, the model is validated. Fig. 8 shows the verification results which indicate the simulated data fit well with the observed data. 


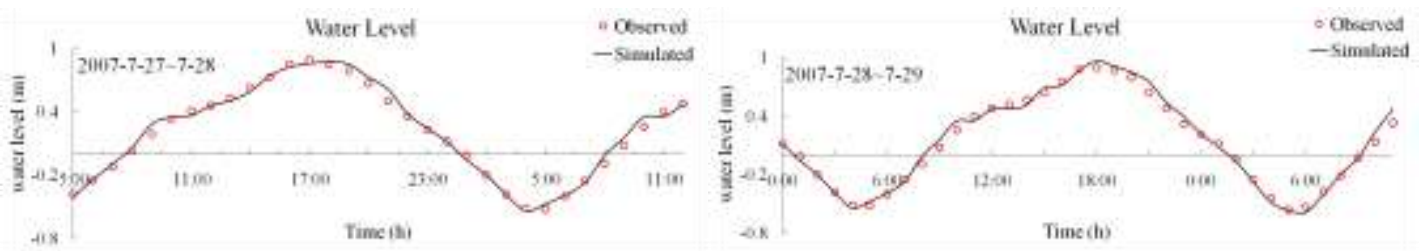

Figure 6. Comparison between simulated and observed time history of water level from 2007-7-27 5:00 to 2007-7-28 11:00 and from 2007-7-28 0:00 to 2007-7-29 11:00 respectively.
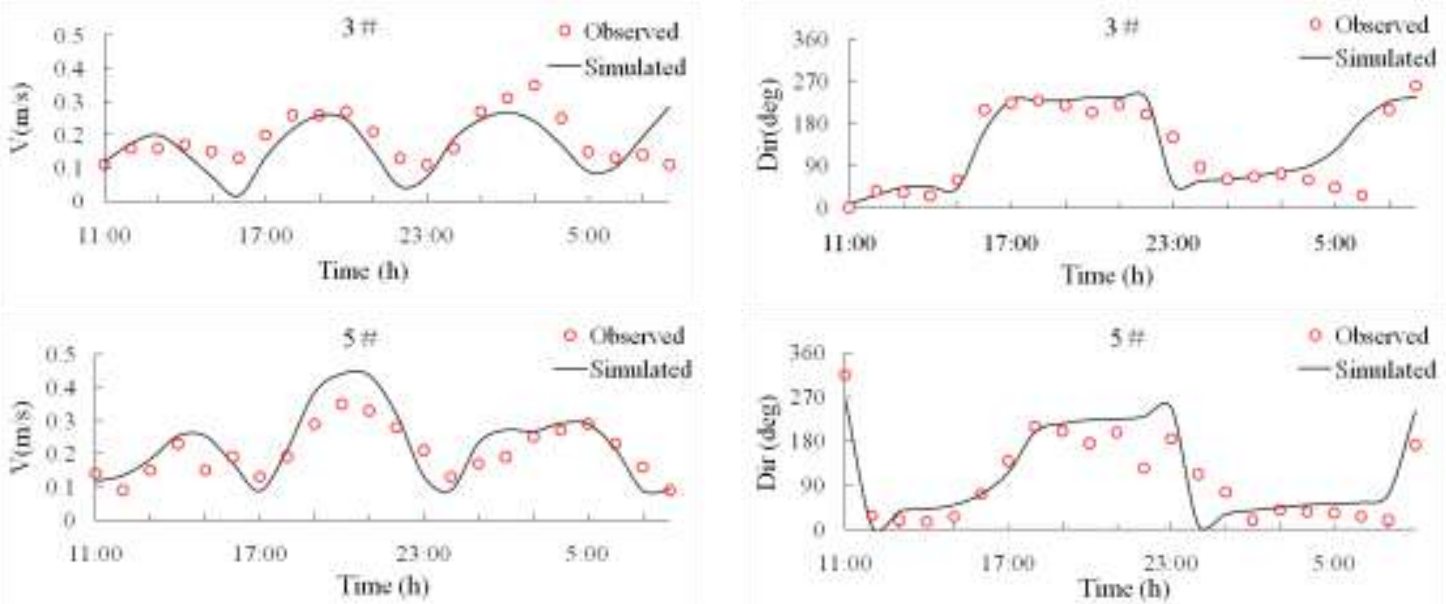

Figure 7. Comparison between simulated and observed time history of tidal current velocity magnitude and direction at station 3 and 5 from 2007-7-28 11:00 to 2007-7-29 5:00 (for model calibration).
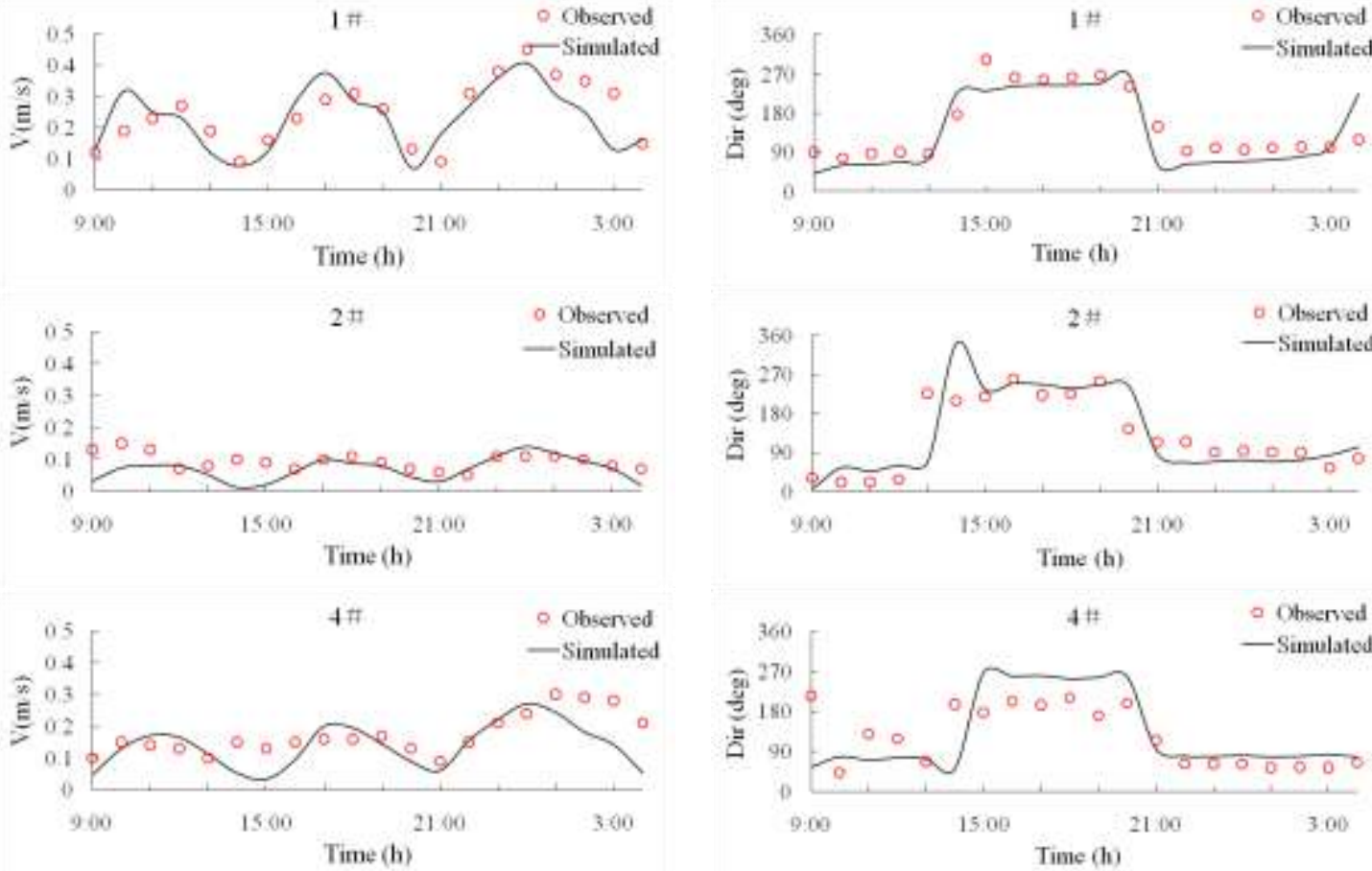

Figure 8. Comparison between simulated and observed time history of tidal current velocity magnitude and direction at station 1, 2 and 4 from 2007-7-27 9:00 to 2007-7-28 3:00 (for model verification). 


\section{Model result and discussion}

According to a primary analysis on stability, environment, sight of the beach, and construction quantity, four project schemes are simulated as shown in Fig. 9. As reference, the current field without project is also simulated, mentioned as scheme 0. Detailed current fields of scheme 0 to 4 are simulated in the small-scale model.

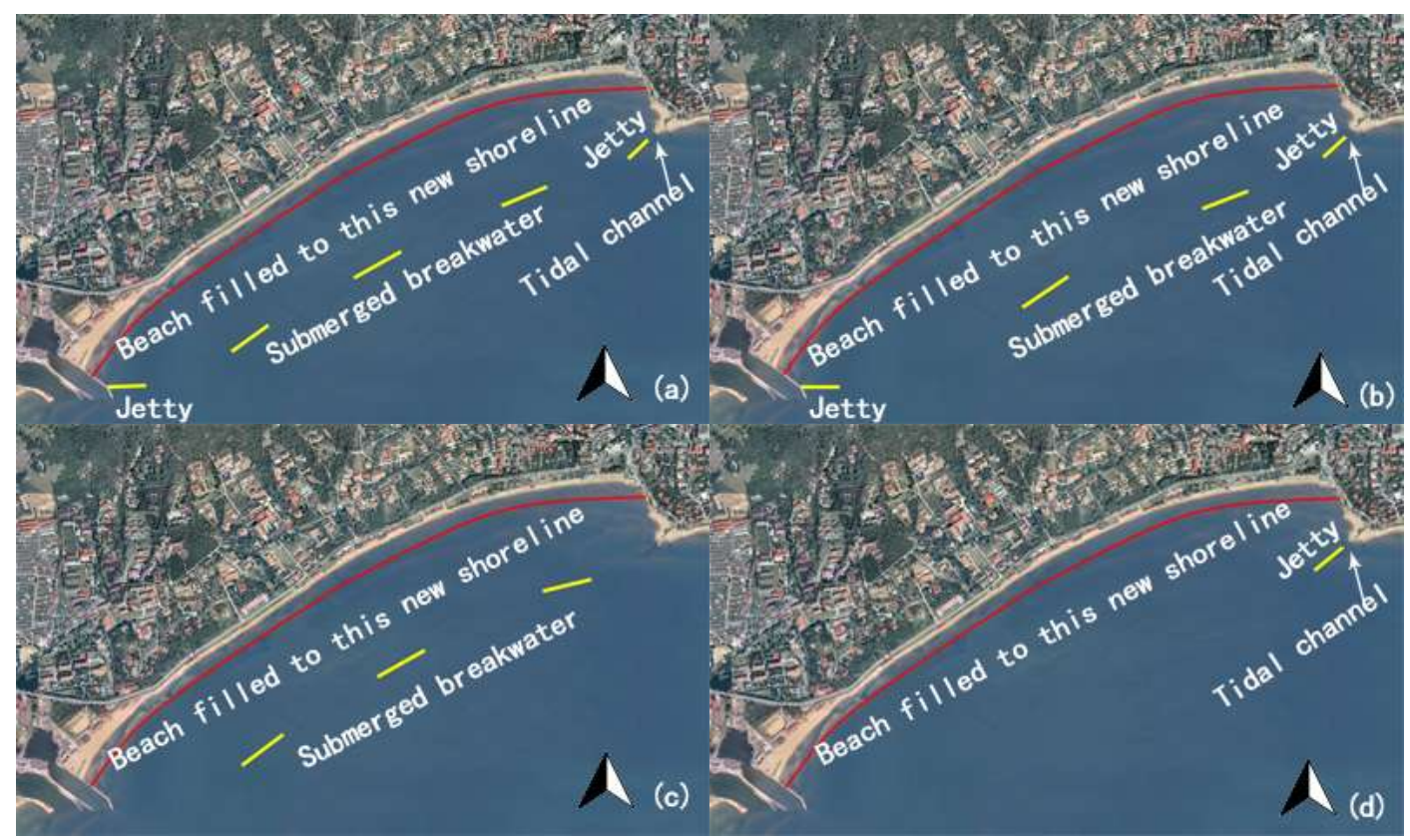

Figure 9. Project schemes for whole-beach-scale project: (a) scheme 1: 50m wide beach nourishment with jetties and 3 submerged breakwaters, (b) scheme 2: $50 \mathrm{~m}$ wide beach nourishment with jetties and 2 submerged breakwaters, (c) scheme $3: 50 \mathrm{~m}$ wide beach nourishment with 3 submerged breakwaters, (d) scheme 4: $50 \mathrm{~m}$ wide beach nourishment with east jetty

Fig. 10 shows the tidal current field at the time of peak flood current and peak ebb current under scheme 0 to 4 . The dominated flood current direction is from NE to SW, and the ebb current direction is from SW to NE. The tidal current velocity behind west jetty in scheme 1 and scheme 2 is slower than that in the schemes without the west jetty, which indicates the west jetty plays a key role in protecting the sheltered area of the cape near Dai River. And the east jetty plays an important role in protecting its sheltered area, for the tidal current velocity behind east jetty in scheme 1 , scheme 2 and scheme 4 is slower than that in the schemes without the east jetty. But the east jetty doesn't have as much protective effect as the west jetty, for it has very little influence on the current field outside of its sheltered area.

Because Fig. 10 shows the qualitative results of the simulation, and in order to show some quantitative results, some observation points arre set as seen in Fig. 11. T1 T2 are the points in the tidal channel. N1 N9 are points in nearshore area along the shoreline from west to east. $\mathrm{J} 1 \sim \mathrm{J} 3$ are the points around west jetty and J4 J6 are the points around east jetty. O1 O5 are the points between or behind three submerged breakwaters, while S1 S5 are the points between or behind two submerged breakwaters. 


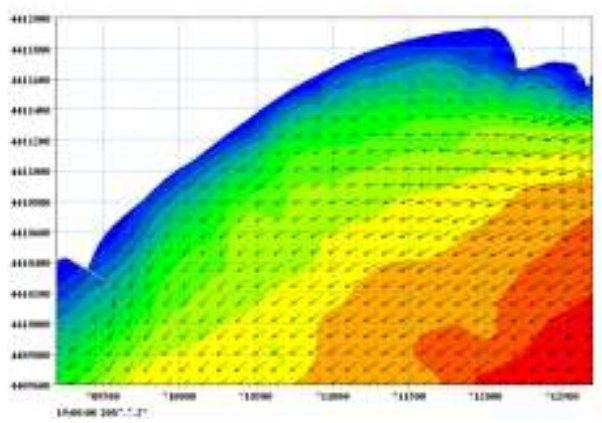

a) peak flood current of scheme 0

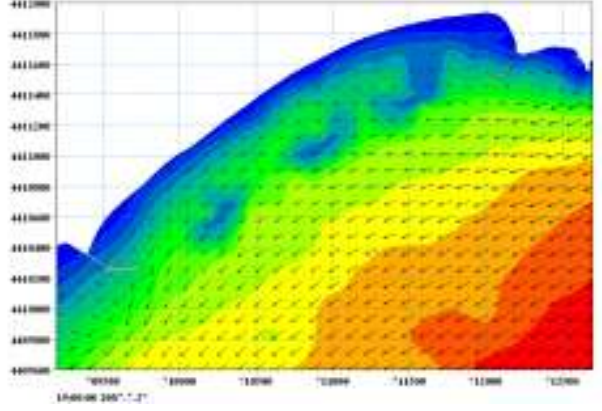

c) peak flood current of scheme 1

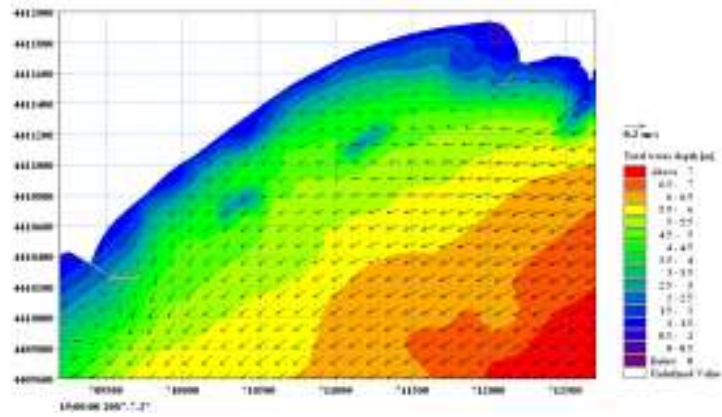

e) peak flood current of scheme 2

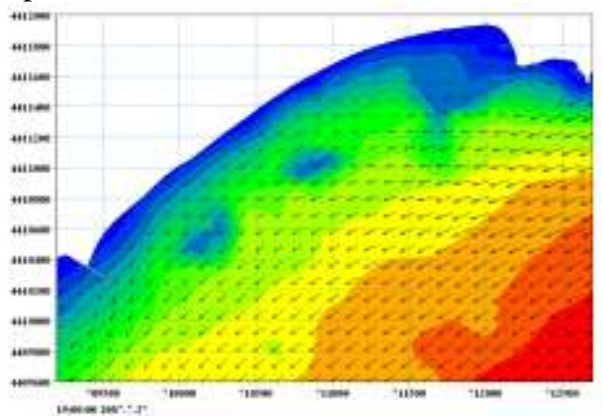

g) peak flood current of scheme 3

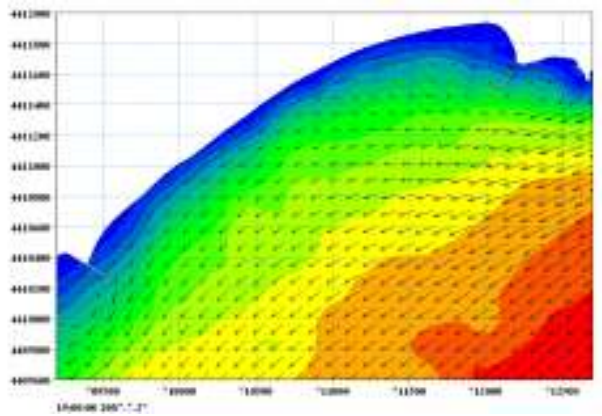

i) peak flood current of scheme 4

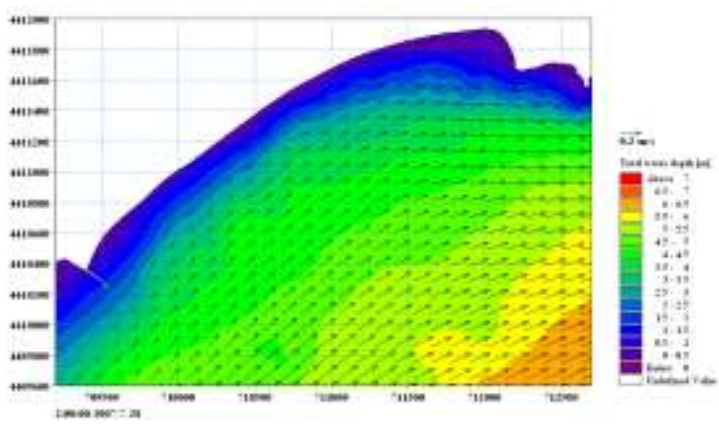

b) peak ebb current of scheme 0

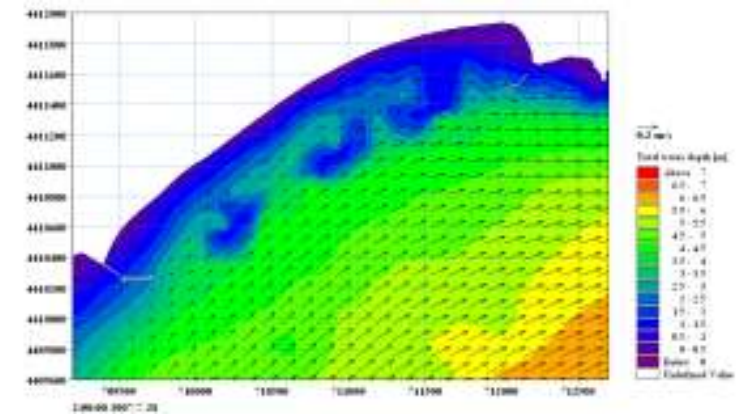

d) peak ebb current of scheme 1

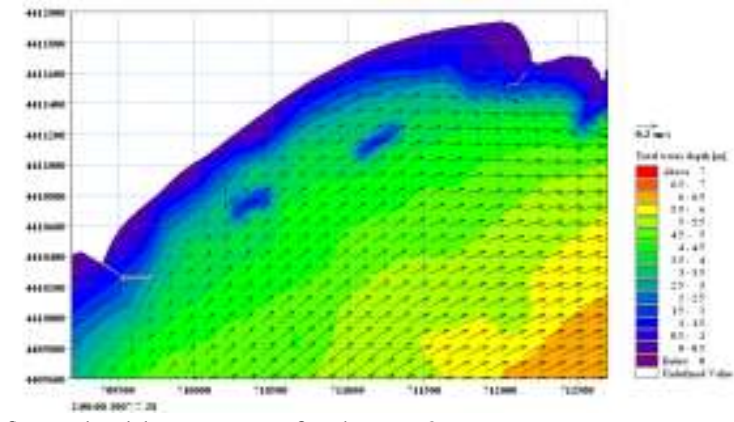

f) peak ebb current of scheme 2

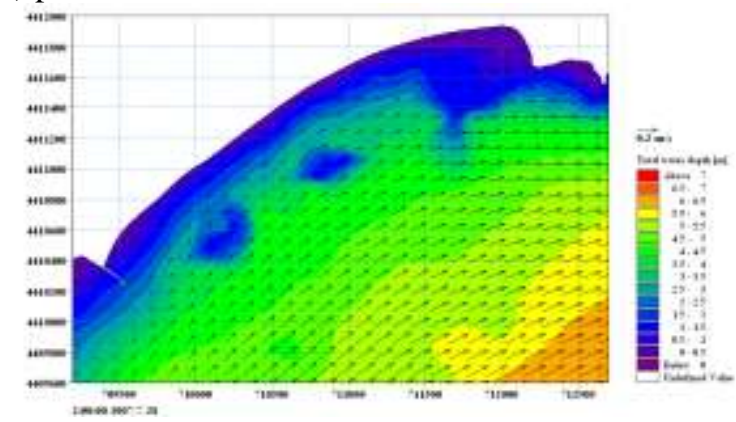

h) peak ebb current of scheme 3

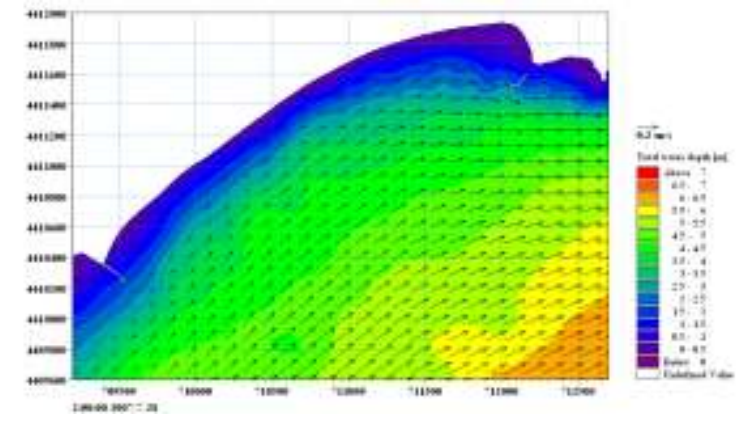

j) peak ebb current of scheme 4

Figure 10. Simulated peak flood and ebb tidal current fields under scheme 0 to 4 . 


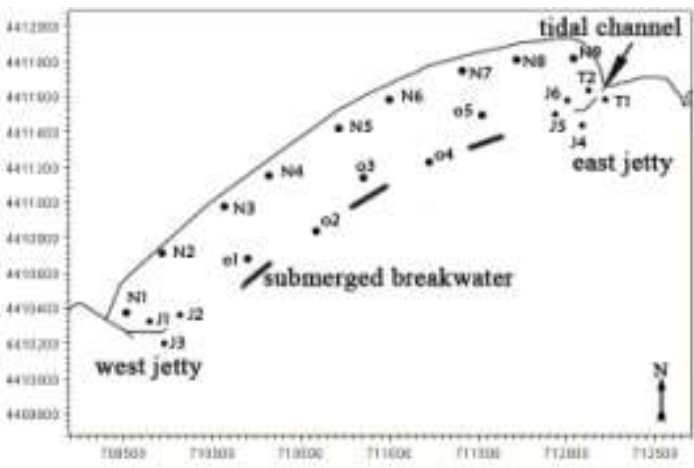

a) observation points of scheme 1 and scheme 3

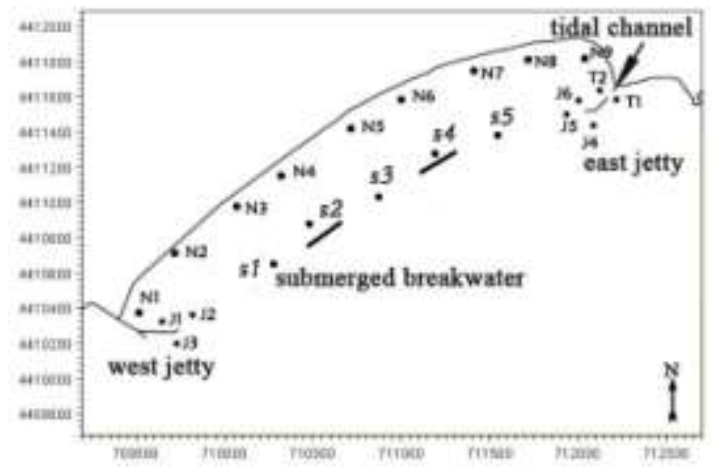

b) observation points of scheme 2

Figure 11. Location of observation points.

Fig. 12 shows the simulation results of tidal current velocity magnitude and direction of point T1 and T2 under scheme 0 to 4 . As seen, the general tidal current velocity magnitude of T1 and T2 in scheme 1 , scheme 2 and scheme 4 reduce significantly while the general tidal current magnitude in scheme 3 reduce a little compared to scheme 0 (natural situation without projects). The peak ebb tidal current velocity of T1 and T2 in scheme 1, scheme 2 and scheme 4 reduced greatly and the magnitude reduce from about $0.15 \mathrm{~m} / \mathrm{s}$ to less than $0.1 \mathrm{~m} / \mathrm{s}$, while the flood tidal current velocity of T1 in scheme 1 and scheme 4 increase a little but no more than $0.1 \mathrm{~m} / \mathrm{s}$. The directions of tidal current velocity of T1 and $\mathrm{T} 2$ in this four schemes change at slack water, especially the tidal current of point T2, which locates in the west of tidal channel, in scheme 2 flow changes from flood to ebb an hour earlier. In a word, the magnitude of tidal current velocity in the tidal channel reduces significantly after the east jetty has been set up and its direction only changes around slack water.
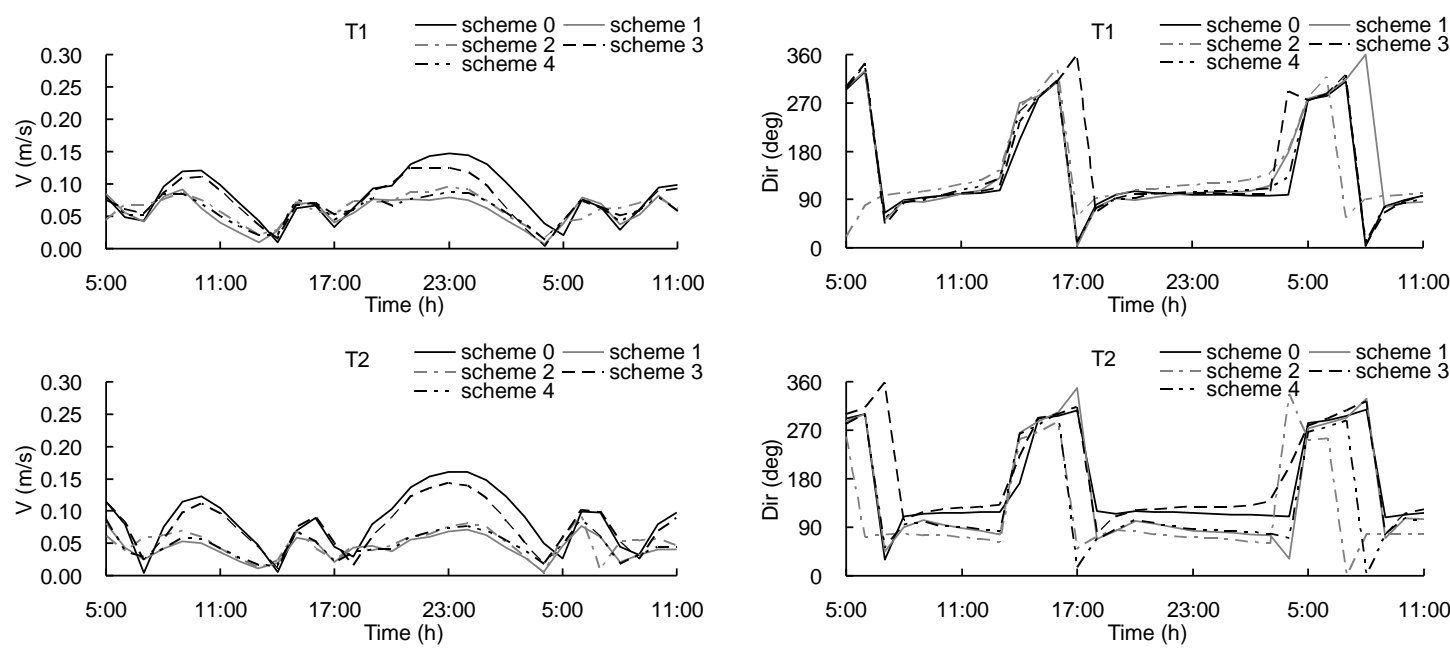

Figure 12. Comparison of tidal current velocity magnitude and direction of observation points locate in the tidal channel in scheme 0 to 4.

Fig. 13 shows the simulation results of tidal current velocity magnitude and direction of point $\mathrm{J} 1$ to J6 in scheme 0 to 4 . J1 and J6 locate behind the west jetty and east jetty, respectively. The magnitude of tidal current velocity of $\mathrm{J} 1$ and $\mathrm{J} 6$ reduce and their directions change a lot when the jetty exists, for example, J1 in scheme 1 and scheme 2 and J6 in scheme 1, scheme 2 and scheme 4, as shown in Fig. 13 $\mathrm{J} 2$ and $\mathrm{J} 5$ locate around the head of west jetty and east jetty, respectively. The magnitude of tidal current velocity of $\mathrm{J} 2$ in scheme 1 and scheme 2 reduce during the modeling period, and the reduction is more significantly in the ebb period. The magnitude of tidal current velocity of J5 in scheme 1 (with east jetty) reduces, while the one in scheme 3 (without the jetty) increases. The direction of tidal current velocity of $\mathrm{J} 2$ and $\mathrm{J} 5$ changes only around slack water. J3 and J4 locate at the sea side of the west jetty and east jetty, respectively. The magnitude of tidal current velocity of J3 changes very little. The 
magnitude of tidal current velocity of $\mathrm{J} 4$ in scheme 1 , scheme 2 and scheme 4 (with east jetty) increases compared with scheme 0 , while it reduces in scheme 3 (without east jetty) in the ebb period. The slack water of $\mathrm{J} 3$ and $\mathrm{J} 4$ become earlier in scheme 1 and scheme 2, respectively.
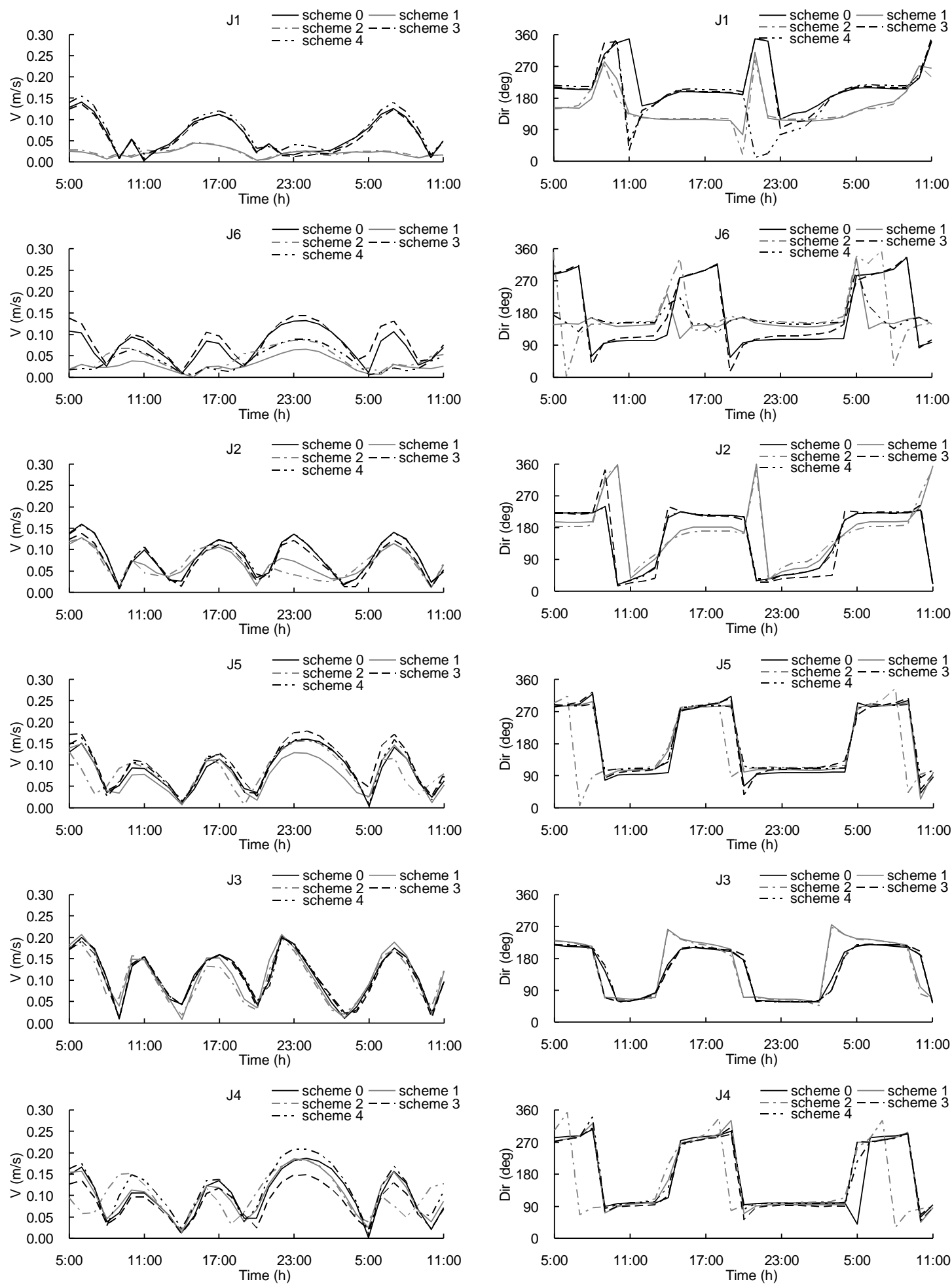

Figure 13. Comparison of tidal current velocity magnitude and direction of observation points $\mathrm{J} 1$ to J6 in scheme 0 to 4 .

Table 1 and Table 2 show the mean flood and ebb tidal current velocities at representative points under scheme 0 to 4 , respectively. Table 3 and Table 4 show the peak flood and ebb tidal current 
velocities of these points. The tidal current velocity between the submerged breakwaters reduces, for example, the tidal current velocity of $\mathrm{O} 2$ and $\mathrm{O} 4$ in scheme 1 and scheme 3 and the tidal current velocity of S3 in scheme 2. In scheme 4, the tidal current velocities near the east jetty namely O5 and S5 increase slightly. The direction of tidal current velocity of the points in the submerged breakwater area changes very little in scheme 1 to 4 compared to the natural situation (scheme 0 ). The tidal current velocity in the nearshore area under scheme 1 and scheme 2 reduces compared to scheme 0 . The value of $\mathrm{N} 1$ and N9, which locate at the headlands, reduce most sharply. The rate of increase of the tidal current velocity of N9, which is near the east headland, reaches $28 \%$ under scheme 3 . Compared to scheme 1, it's easy to find out that the construction of the east jetty protects the West Beach efficiently. Compared to scheme 4, in which the tidal current velocity of N9 reduces most, the protect range of the east jetty is limited and it doesn't work well without other structures (eg. submerged breakwater).

\begin{tabular}{|c|c|c|c|c|c|c|c|c|c|}
\hline \multicolumn{2}{|c|}{ Table 1. Mean flood tidal current velocities at representative points under scheme 0 to 4 } \\
\hline \multirow{2}{*}{ spot } & scheme0 & \multicolumn{2}{|c|}{ scheme1 } & \multicolumn{2}{|c|}{ scheme2 } & \multicolumn{2}{|c|}{ scheme3 } & \multicolumn{2}{c|}{ scheme4 } \\
\cline { 2 - 10 } & $\mathrm{V}(\mathrm{m} / \mathrm{s})$ & $\mathrm{V}(\mathrm{m} / \mathrm{s})$ & $\Delta(\%)$ & $\mathrm{V}(\mathrm{m} / \mathrm{s})$ & $\Delta(\%)$ & $\mathrm{V}(\mathrm{m} / \mathrm{s})$ & $\Delta(\%)$ & $\mathrm{V}(\mathrm{m} / \mathrm{s})$ & $\Delta(\%)$ \\
\hline $\mathrm{N} 1$ & 0.032 & 0.012 & -61.49 & 0.011 & -66.74 & 0.035 & 8.84 & 0.044 & 36.54 \\
\hline $\mathrm{N} 2$ & 0.051 & 0.042 & -18.65 & 0.033 & -34.95 & 0.047 & -7.74 & 0.052 & 2.20 \\
\hline $\mathrm{N} 3$ & 0.052 & 0.051 & -3.42 & 0.044 & -15.96 & 0.064 & 22.88 & 0.057 & 8.12 \\
\hline $\mathrm{N} 4$ & 0.054 & 0.053 & -1.41 & 0.044 & -18.78 & 0.047 & -13.87 & 0.052 & -4.09 \\
\hline $\mathrm{N} 5$ & 0.046 & 0.040 & -13.10 & 0.041 & -10.93 & 0.045 & -3.75 & 0.046 & 0.11 \\
\hline $\mathrm{N} 6$ & 0.057 & 0.053 & -7.61 & 0.041 & -27.65 & 0.043 & -24.88 & 0.046 & -18.66 \\
\hline $\mathrm{N} 7$ & 0.045 & 0.041 & -7.91 & 0.035 & -22.15 & 0.037 & -17.61 & 0.036 & -20.29 \\
\hline $\mathrm{N} 8$ & 0.041 & 0.045 & 8.87 & 0.016 & -60.59 & 0.039 & -5.45 & 0.031 & -23.87 \\
\hline $\mathrm{N} 9$ & 0.025 & 0.019 & -24.62 & 0.013 & -49.15 & 0.032 & 28.52 & 0.022 & -10.79 \\
\hline O1(S1) & $0.086(0.077)$ & 0.104 & 20.93 & 0.064 & -16.88 & 0.109 & 26.74 & $0.086(0.077)$ & $0.00(0.00)$ \\
\hline O2(S2) & $0.088(0.080)$ & 0.066 & -25.00 & 0.079 & -1.25 & 0.071 & -19.32 & $0.087(0.081)$ & $-1.14(1.25)$ \\
\hline O3(S3) & $0.069(0.078)$ & 0.063 & -8.70 & 0.068 & -12.82 & 0.069 & 0.00 & $0.07(0.077)$ & $1.45(-1.28)$ \\
\hline O4(S4) & $0.073(0.072)$ & 0.058 & -20.55 & 0.070 & -2.78 & 0.062 & -15.07 & $0.071(0.072)$ & $-2.74(0.00)$ \\
\hline O5(S5) & $0.064(0.069)$ & 0.074 & 15.63 & 0.067 & -2.90 & 0.059 & -7.81 & $0.064(0.073)$ & $0.00(5.80)$ \\
\hline
\end{tabular}

\begin{tabular}{|c|c|c|c|c|c|c|c|c|c|}
\hline \multicolumn{2}{|c|}{ Table 2. Mean ebb tidal current velocities at representative points under scheme 0 to 4 } \\
\hline \multirow{2}{*}{ spot } & scheme0 & scheme1 & \multicolumn{2}{|c|}{ scheme2 } & \multicolumn{2}{|c|}{ scheme3 } & \multicolumn{2}{c|}{ scheme4 } \\
\cline { 2 - 10 } & $\mathrm{V}(\mathrm{m} / \mathrm{s})$ & $\mathrm{V}(\mathrm{m} / \mathrm{s})$ & $\Delta(\%)$ & $\mathrm{V}(\mathrm{m} / \mathrm{s})$ & $\Delta(\%)$ & $\mathrm{V}(\mathrm{m} / \mathrm{s})$ & $\Delta(\%)$ & $\mathrm{V}(\mathrm{m} / \mathrm{s})$ & $\Delta(\%)$ \\
\hline $\mathrm{N} 1$ & 0.018 & 0.008 & -55.56 & 0.008 & -55.56 & 0.017 & -5.56 & 0.018 & 0.00 \\
\hline $\mathrm{N} 2$ & 0.039 & 0.028 & -28.21 & 0.029 & -25.64 & 0.035 & -10.26 & 0.039 & 0.00 \\
\hline $\mathrm{N} 3$ & 0.046 & 0.049 & 6.52 & 0.044 & -4.35 & 0.052 & 13.04 & 0.048 & 4.35 \\
\hline $\mathrm{N} 4$ & 0.053 & 0.049 & -7.55 & 0.053 & 0.00 & 0.049 & -7.55 & 0.050 & -5.66 \\
\hline $\mathrm{N} 5$ & 0.042 & 0.049 & 16.67 & 0.038 & -9.52 & 0.052 & 23.81 & 0.044 & 4.76 \\
\hline $\mathrm{N} 6$ & 0.050 & 0.048 & -4.00 & 0.048 & -4.00 & 0.044 & -12.00 & 0.049 & -2.00 \\
\hline $\mathrm{N} 7$ & 0.049 & 0.050 & 2.04 & 0.050 & 2.04 & 0.043 & -12.24 & 0.047 & -4.08 \\
\hline $\mathrm{N} 8$ & 0.059 & 0.053 & -10.17 & 0.044 & -25.42 & 0.057 & -3.39 & 0.050 & -15.25 \\
\hline $\mathrm{N} 9$ & 0.041 & 0.029 & -29.27 & 0.048 & 17.07 & 0.052 & 26.83 & 0.037 & -9.76 \\
\hline O1(S1) & $0.064(0.074)$ & 0.082 & 28.13 & 0.079 & 6.76 & 0.084 & 31.25 & $0.062(0.075)$ & $-3.13(1.35)$ \\
\hline O2(S2) & $0.070(0.057)$ & 0.058 & -17.14 & 0.070 & 22.81 & 0.063 & -10.00 & $0.071(0.058)$ & $1.43(1.75)$ \\
\hline O3(S3) & $0.061(0.067)$ & 0.062 & 1.64 & 0.067 & 0.00 & 0.068 & 11.48 & $0.063(0.068)$ & $3.28(1.49)$ \\
\hline O4(S4) & $0.071(0.073)$ & 0.054 & -23.94 & 0.071 & -2.74 & 0.060 & -15.49 & $0.073(0.076)$ & $2.82(4.11)$ \\
\hline O5(S5) & $0.070(0.079)$ & 0.073 & 4.29 & 0.074 & -6.33 & 0.065 & -7.14 & $0.072(0.083)$ & $2.86(5.06)$ \\
\hline
\end{tabular}




\begin{tabular}{|c|c|c|c|c|c|c|c|c|c|}
\hline \multicolumn{7}{|c|}{ Table 3. Peak flood tidal current velocities at representative points under scheme 0 to 4 } \\
\hline \multirow{2}{*}{ spot } & scheme0 & scheme1 & \multicolumn{2}{|c|}{ scheme2 } & \multicolumn{2}{c|}{ scheme3 } & \multicolumn{2}{c|}{ scheme4 } \\
\cline { 2 - 10 } & $\mathrm{V}(\mathrm{m} / \mathrm{s})$ & $\mathrm{V}(\mathrm{m} / \mathrm{s})$ & $\Delta(\%)$ & $\mathrm{V}(\mathrm{m} / \mathrm{s})$ & $\Delta(\%)$ & $\mathrm{V}(\mathrm{m} / \mathrm{s})$ & $\Delta(\%)$ & $\mathrm{V}(\mathrm{m} / \mathrm{s})$ & $\Delta(\%)$ \\
\hline T1 & 0.077 & 0.079 & 2.60 & 0.073 & -5.19 & 0.074 & -3.90 & 0.078 & 1.30 \\
\hline T2 & 0.100 & 0.077 & -23.00 & 0.092 & -8.00 & 0.102 & 2.00 & 0.087 & -13.00 \\
\hline N1 & 0.051 & 0.022 & -56.86 & 0.021 & -58.82 & 0.057 & 11.76 & 0.067 & 31.37 \\
\hline N2 & 0.089 & 0.069 & -22.47 & 0.059 & -33.71 & 0.092 & 3.37 & 0.090 & 1.12 \\
\hline N3 & 0.096 & 0.089 & -7.29 & 0.085 & -11.46 & 0.105 & 9.37 & 0.099 & 3.13 \\
\hline N4 & 0.099 & 0.090 & -9.09 & 0.095 & -4.04 & 0.087 & -12.12 & 0.091 & -8.08 \\
\hline N5 & 0.075 & 0.074 & -1.33 & 0.072 & -4.00 & 0.079 & 5.33 & 0.074 & -1.33 \\
\hline N6 & 0.081 & 0.077 & -4.94 & 0.071 & -12.35 & 0.070 & -13.58 & 0.072 & -11.11 \\
\hline N7 & 0.071 & 0.064 & -9.86 & 0.060 & -15.49 & 0.064 & -9.86 & 0.055 & -22.54 \\
\hline N8 & 0.060 & 0.067 & 11.67 & 0.036 & -40.00 & 0.069 & 15.00 & 0.046 & -23.33 \\
\hline N9 & 0.032 & 0.041 & 28.13 & 0.040 & 25.00 & 0.046 & 43.75 & 0.041 & 28.13 \\
\hline O1(S1) & $0.136(0.136)$ & 0.180 & 32.35 & 0.116 & -14.71 & 0.186 & 36.76 & $0.134(0.135)$ & $-1.47(-0.74)$ \\
\hline O2(S2) & $0.138(0.126)$ & 0.103 & -25.36 & 0.132 & 4.76 & 0.109 & -21.01 & $0.136(0.124)$ & $-1.45(-1.59)$ \\
\hline O3(S3) & $0.114(0.123)$ & 0.107 & -6.14 & 0.112 & -8.94 & 0.118 & 3.51 & $0.114(0.121)$ & $0.00(-1.63)$ \\
\hline O4(S4) & $0.121(0.120)$ & 0.098 & -19.01 & 0.120 & 0.00 & 0.105 & -13.22 & $0.117(0.119)$ & $-3.31(-0.83)$ \\
\hline O5(S5) & $0.112(0.120)$ & 0.130 & 16.07 & 0.115 & -4.17 & 0.091 & -18.75 & $0.109(0.125)$ & $-2.68(4.17)$ \\
\hline
\end{tabular}

\begin{tabular}{|c|c|c|c|c|c|c|c|c|c|}
\hline \multicolumn{2}{|c|}{ Table 4. Peak ebb tidal current velocities at representative points under scheme 0 to 4} \\
\hline \multirow{2}{*}{ spot } & scheme0 & \multicolumn{2}{|c|}{ scheme1 } & \multicolumn{2}{|c|}{ scheme2 } & \multicolumn{2}{|c|}{ scheme3 } & \multicolumn{2}{c|}{ scheme4 } \\
\cline { 2 - 10 } & $\mathrm{V}(\mathrm{m} / \mathrm{s})$ & $\mathrm{V}(\mathrm{m} / \mathrm{s})$ & $\Delta(\%)$ & $\mathrm{V}(\mathrm{m} / \mathrm{s})$ & $\Delta(\%)$ & $\mathrm{V}(\mathrm{m} / \mathrm{s})$ & $\Delta(\%)$ & $\mathrm{V}(\mathrm{m} / \mathrm{s})$ & $\Delta(\%)$ \\
\hline $\mathrm{N} 1$ & 0.019 & 0.014 & -26.32 & 0.018 & -5.26 & 0.018 & -5.26 & 0.019 & 0.00 \\
\hline $\mathrm{N} 2$ & 0.057 & 0.044 & -22.81 & 0.047 & -17.54 & 0.059 & 3.51 & 0.058 & 1.75 \\
\hline $\mathrm{N} 3$ & 0.089 & 0.094 & 5.62 & 0.076 & -14.61 & 0.096 & 7.87 & 0.092 & 3.37 \\
\hline $\mathrm{N} 4$ & 0.100 & 0.097 & -3.00 & 0.093 & -7.00 & 0.083 & -17.00 & 0.092 & -8.00 \\
\hline $\mathrm{N} 5$ & 0.073 & 0.078 & 6.85 & 0.067 & -8.22 & 0.081 & 10.96 & 0.076 & 4.11 \\
\hline $\mathrm{N} 6$ & 0.095 & 0.092 & -3.16 & 0.079 & -16.84 & 0.079 & -16.84 & 0.080 & -15.79 \\
\hline $\mathrm{N} 7$ & 0.087 & 0.094 & 8.05 & 0.079 & -9.20 & 0.073 & -16.09 & 0.076 & -12.64 \\
\hline $\mathrm{N} 8$ & 0.094 & 0.094 & 0.00 & 0.065 & -30.85 & 0.102 & 8.51 & 0.078 & -17.02 \\
\hline $\mathrm{N} 9$ & 0.063 & 0.050 & -20.63 & 0.064 & 1.59 & 0.090 & 42.86 & 0.055 & -12.70 \\
\hline O1(S1) & $0.136(0.139)$ & 0.175 & 28.68 & 0.143 & 2.88 & 0.176 & 29.41 & $0.131(0.142)$ & $-3.68(2.16)$ \\
\hline O2(S2) & $0.154(0.119)$ & 0.122 & -20.78 & 0.142 & 19.33 & 0.127 & -17.53 & $0.153(0.122)$ & $-0.65(2.52)$ \\
\hline O3(S3) & $0.127(0.144)$ & 0.125 & -1.57 & 0.135 & -6.25 & 0.130 & 2.36 & $0.127(0.139)$ & $0.00(-3.47)$ \\
\hline O4(S4) & $0.142(0.141)$ & 0.105 & -26.06 & 0.135 & -4.26 & 0.112 & -21.13 & $0.138(0.141)$ & $-2.82(0.00)$ \\
\hline O5(S5) & $0.129(0.145)$ & 0.139 & 7.75 & 0.131 & -9.66 & 0.118 & -8.53 & $0.125(0.144)$ & $-3.10(-0.69)$ \\
\hline
\end{tabular}

\section{CONCLUDING REMARKS}

A two-dimensional numerical tidal current model is developed to simulate the tidal current in West Beach of Beidaihe at first. Then the comparison is made among four nourishment schemes. The research shows that: (1) the east jetty plays a key role in the protection of West Beach; (2) it is feasible to protect and enlarge the West Beach by beach nourishment along with jetties and submerged breakwaters; and (3) after nourishment project, the tidal current velocity reduces obviously in the near shore area, which can protect the West Beach.

This paper is part of the preliminary research achievements on beach nourishment projects in Beidaihe, China. This preliminary study contents contain the sub-main hydrodynamic force of tidal current, which is discussed in this paper, the shoreline change prediction based on one-line theory, whose partial 
achievement has already been published (Kuang et al., 2010) and the interaction of all these physical factors. Further study on the beach profile morphology changes by the main hydrodynamic force of wave will be issued soon.

\section{ACKNOWLEDGMENTS}

The authors thank the Department of Land and Resources of Hebei Province (Project No.: HEBEIGT2006ZT and HEBEIGT2008-2903) and State Oceanic Administration of the People's Republic of China (Project No.: 200905008-05) for the financial support.

\section{REFERENCES}

Blumberg, A.F., Mellor, G.L. 1987. A description of a three-dimensional coastal ocean circulation model. In: N.S. Heaps (eds), Three-dimensional coastal ocean models, American Geophysical Union, Washington, D.C., 1987: 1-16

Bird, E.C.F., 1985. Coastline Changes: a Global Review. Wiley-Interscience, Chichester.

Bird, E. 2008. Coastal Geomorphology: an introduction, John Wiley \& Sons Ltd, Chichester, 27-28 pp.

Cao, D.M., and Fang, G.H. 1990. A numerical model for tides and tidal currents in northern South China Sea, Tropic Oceanology, 9, 63-70. (in Chinese)

Chen C., Liu H. 2003. An unstructured grid, finite-volume, three-dimensional, primitive equations ocean model: application to coastal ocean and estuaries, Journal of Atmospheric and Oceanic Technology, Vol. 20: 159-186

Davis Jr R.A. and FitzGerald D.M. 2004. Beaches and Coasts, Blackwell Science Ltd, 208 pp.

DHI Hydraulics. 2005. MIKE 21 \& MIKE 3 FLOW MODEL Hydrodynamic Module Scientific Documentation. Demark: DHI Water \& Environment.

Gu, J., and Kuang, C.P. 1996. A far-field numerical model for a jet pollution into tide flows, The Ocean Engineering, 14, 88-96.

Hamrick, J.M. 1992. A three-dimensional environmental fluid dynamics computer code: theoretical and computation aspects, Special Report No.317 in Applied Marine Science and Ocean Engineering, Virginia Institute of Marine Science School of Marine Science, The College of William and Mary Gloucester Point, VA 23062.

Kuang, C.P., Pan, Y., Zhang, Liu, S.G., Yang, Y.X. and Zhang, J.B. 2010. Shoreline change modeling on emergency beach nourishment project on West Beach of Beidaihe, China. China Ocean Engineering, 24, 277-289.

Liu, H., Wu, Q.S., Luo, Z.B., and Pan, W.R. 2009. Model study on the tidal regime and pollutant transport in the Fuqing Bay, Journal of Xiamen University (Natural Science), 48, 139-143. (in Chinese)

Luettich, R.A., Westerink, J.J., and Scheffner, N.W. 1991. ADCIRC: an advanced three-dimensional circulation model for shelves, coasts and estuaries, Coast. Engrg. Res. Ct., US Army Engs. Wtrways. Experiment Station, Vicksburg, MS.

Qinhuangdao Mineral Resource and Hydrogeological Brigade. 2009. The design book for the emergency projects of SC bathing place and Tiger Stone bathing place in middle beach of Beidaihe, Qinhuangdao City, China. (in Chinese)

Sheng, Y.P. 1986. CH3D: A three-dimensional numerical model of coastal and estuarine circulation and transport in generalized curvilinear grids, Technical Report No. 587, Aeronautical Research Associates of Princeton, Inc., New Jersey.

Shi, Z., and Li, S.S. 2003. A two-dimensional vertical numerical model of tidal flow and its application to the north passage of the Changjiang River Estuary, Marine Science Bulletin, 22, 1-8. (in Chinese)

Van der Salm, J. and Unal, O., 2003. Towards a common Mediterranean framework for beach nourishment projects. Journal of Coastal Conservation 9: pp. 35-42.

Wan, J.M., and Li, S.Y. 2000. Mathematical Simulation of Environmental Impact on Adjacent Sea Area by Henmen Inning Project, Shanghai Environmental Sciences, 3, 105-107. (in Chinese)

WL | Delft Hydraulics. 2006. User Manual Delft3D-FLOW.

Zhang Y.L., Baptista A.M., Myers E.P. 2004. A cross-scale model for 3D baroclinic circulation in estuary-plume-shelf systems: I. Formulation and skill assessment, Cont. Shelf Res., 24: 2187-2214.

Zhang, Y., Sun, Y.L., Zhang, X.Q., and Liu, X.D. 2007. Numerical Simulation of the Tidal Current in the Guangxi Offshore Area, Marine Science Bulletin, 26, 17-21. (in Chinese)

Zhang Y.L, Baptista A.M. 2008. SELFE: A simi-implicit Eulerian-Lagrangian Finite-element model for cross-scale ocean circulation, Ocean Modeling, Vol. 21: 71-96. 